\title{
Direct torque control of doubly fed induction machine
}

\author{
F. BONNET*, P.E. VIDAL, and M. PIETRZAK-DAVID \\ Laboratoire d'Électrotechnique et d'Électronique Industrielle, Institut National Polytechnique, Toulouse Cedex, 31071 France
}

\begin{abstract}
This paper presents novel bi-converter structure to supply the Doubly Fed Induction Machine (DFIM). Two Voltage Source Inverters (VSI) feed the stator and rotor windings. The outputs of two VSI are combined electro-mechanically in the machine and, as a result, novel features can be obtained. For example, for high power drive applications, this configuration use two inverters dimensioned for a half of the DFIM power. A new Dual-Direct Torque Control scheme is developed with flux model of DFIM. Two Switching Tables (ST) linked to VSI are defined for stator and rotor flux vector control. Experimental and simulation results confirm good dynamic behaviour in the four quadrants of the speed-torque plane. Moreover, experimental results show the correct flux vector control behaviour and speed tracking performances.
\end{abstract}

Key words: direct torque control, doubly fed induction machine, switching tables, voltage source inverters, flux model.

\section{Introduction}

This paper presents a novel Doubly Fed Induction Machine (DFIM) control strategy using Direct Torque Control (DTC) linked with two Switching Tables. This method called DualDTC of DFIM is based on interaction between two Switching Tables which control stator and rotor flux vector. It can be applied to DFIM control in wide variable speed range.

In the works $[1,2]$ a study on a DFIM with constant stator frequency and field oriented rotor current control is described. DFIM stator is directly supplied by the grid and a cyclo-converter feeds the rotor windings. The disadvantage of this configuration is restricted speed operating range which is limited to $20-25 \%$ around the nominal speed.

A new high-power inverter drive system has been presented in [3]. The authors used a DFIM configuration supplied by Pulse Width Modulation (PWM) inverters with current controllers. The advantage of this configuration is the use of the full speed control range.

In this work, we use configuration shown in Fig 1. Each side of the DFIM is fed by an AC-to-AC converter with DClink. Both DC-link voltage levels are deduced from the DFIM design. The stator and the rotor windings have different voltage rating, therefore, a step-down transformer between the AC network and the 3-phase rectifier of the rotor winding supply is added.

This drive can be applied in industry, such as steel rolling mill or marine propulsion systems. In our study, we proposed to replace current controlled PWM inverters studied in [3], by a DTC strategy. DTC allows controlling electromagnetic torque and flux magnitude directly without use of current control loops. According to [4], the main advantages of DTC applied to squirrel induction machine are:

- DTC has a simple and robust control structure; however, the performance of DTC strongly depends on the quality of the estimation of the actual stator flux and torque.
- DTC with switching tables provide excellent torque dynamics.

In this study, we propose separate control of stator and rotor flux. In fact, in order to applied DTC strategy to this configuration, we define a first switching table to control the stator flux vector, and a second switching table to control the rotor flux vector. The next part of the control strategy makes possible to control interaction between both flux vectors. Consequently, we are able to control the electromagnetic torque and to regulate the mechanical speed. This is presented in Section 4.

The validation of the presented Dual-DTC scheme has been performed on an experimental set-up composed of:

- DFIM (4 kW) and a incremental coder (1024 pts)

- Two VSI with Insulated Grid Bipolar Transistor (IGBT)

- Control algorithm implemented by a Digital Signal Processor (DSP) and a Field Programmable Gate Array (FPGA).

The simulations and experimental results shown in Section 5 illustrate operation of variable speed drive and vector flux control.

\section{General principles}

Using stator $\overrightarrow{\Phi_{s}}$ and rotor $\overrightarrow{\Phi_{r}}$ flux vectors as state variables, the DFIM electromagnetic torque can be expressed such as:

$$
\begin{aligned}
\overrightarrow{T_{e m}} & =\frac{3}{2} \frac{N_{p} M}{\sigma L_{s} L r}\left(\overrightarrow{\Phi_{s}} \wedge \overrightarrow{\Phi_{r}}\right) \\
\left\|\overrightarrow{T_{e m}}\right\| & =K \cdot\left\|\overrightarrow{\Phi_{s}}\right\| \cdot\left\|\overrightarrow{\Phi_{r}}\right\| \sin (\gamma) .
\end{aligned}
$$

Where $T_{e m}$ is the electromagnetic torque, $N_{p}$ is the number of pole pairs, $L_{s}, L_{r}$ are the stator and rotor self inductances, $M$ is the mutual inductance, and $\sigma=1-M^{2} /\left(L_{s} . L_{r}\right)$ is the leakage factor. $\overrightarrow{\Phi_{s}}$ and $\overrightarrow{\Phi_{r}}$ are the stator and rotor flux space vectors and $\gamma$ is the angle between flux as shown in Fig. 2. This angle

*e-mail: bonnet@leei.enseeiht.fr 
is referred as torque angle. The constant $\mathrm{K}$ is defined as below:

$$
K=\frac{3}{2} \frac{N_{p} M}{\sigma L_{s} L r}
$$

The goal of this study is to design a fast and robust DFIM control system. This means that the electromagnetic torque have to be controlled. Indeed, the main idea is to maintain $\left\|\overrightarrow{\Phi_{s}}\right\|$ and $\left\|\overrightarrow{\Phi_{r}}\right\|$ to their nominal values and to control the electromagnetic torque by adjusting the torque angle $\gamma$. Consequently, we have to regulate flux vectors. DTC strategy applied to this system will provide fast and robust torque and flux responses.

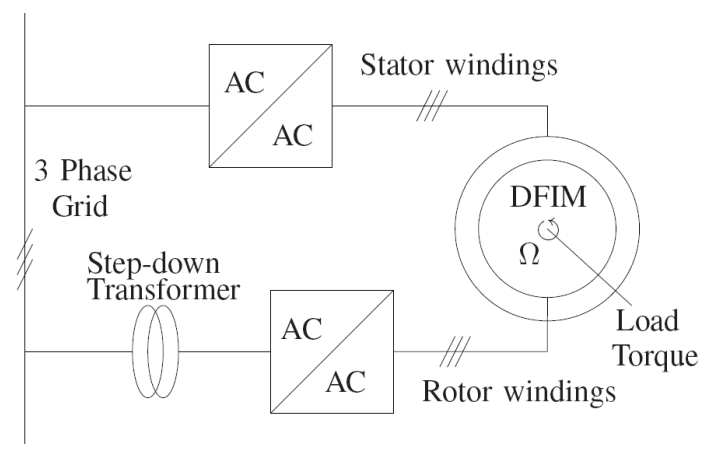

Fig. 1. General diagram of the studied DFIM configuration

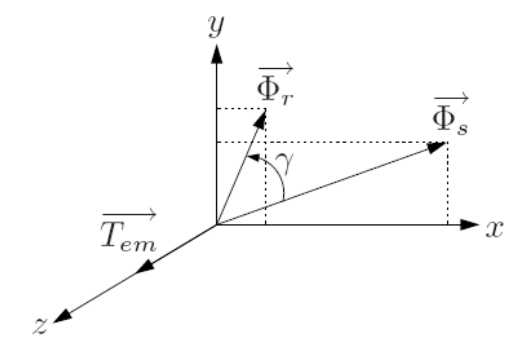

Fig. 2. Flux vector diagram representation and torque production in DFIM

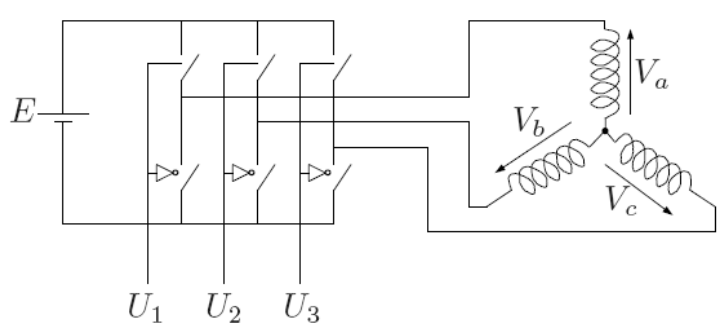

Fig. 3. Stator (or rotor) windings scheme with VSI

\section{System model}

3.1. VSI model. The first VSI is connected to the stator windings and the second one to the rotor windings. Apart from the difference of voltage levels of the DC buses, the stator and rotor VSI are identical. Figure 3 shows a simplified scheme which represents one side of DFIM windings with its own inverter. $U_{1}, U_{2}$ and $U_{3}$ are the switching sequence sent to the
IGBT gates. Moreover, the stator or rotor star voltages are noted $V_{a}, V_{b}, V_{c}$, and the DC bus voltage $E$. In this study we consider an ideal DC supply.

We define the voltage vector as:

$$
\begin{gathered}
\vec{V}=\frac{2}{3}\left(\vec{a}^{0} V_{a}+\vec{a}^{1} \cdot V_{b}+\vec{a}^{2} \cdot V_{c}\right) \\
\text { with }\left\{\begin{array}{l}
\vec{a}=\Re\left(e^{j \frac{2 \Pi}{3}}\right) \vec{x}+\Im\left(e^{j \frac{2 \Pi}{3}}\right) \vec{y} \\
\text { and } j^{2}=-1 .
\end{array}\right.
\end{gathered}
$$

Figure 4 represents VSI voltage vectors in a stationary reference frame $(\vec{x} ; \vec{y})$. The two zero vectors $\vec{V}_{0}$ and $\vec{V}_{7}$ are not represented.

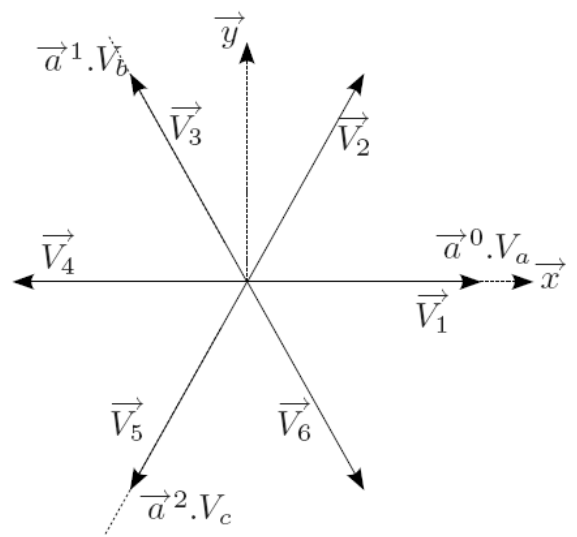

Fig. 4. Representation of voltage vectors

Table 1 is deduced according to the switching sequence.

Table 1

Voltage table

\begin{tabular}{ccccccc}
\hline \hline Voltage vector & $U_{1}$ & $U_{2}$ & $U_{3}$ & $\vec{a}^{0} \cdot V_{a}$ & $\vec{a}^{1} \cdot V_{b}$ & $\vec{a}^{2} \cdot V_{c}$ \\
\hline$V_{0}$ & 0 & 0 & 0 & 0 & 0 & 0 \\
$V_{1}$ & 1 & 0 & 0 & $2 E / 3$ & 0 & 0 \\
$V_{2}$ & 1 & 1 & 0 & $2 E / 3$ & $2 E / 3$ & 0 \\
$V_{3}$ & 0 & 1 & 0 & 0 & $2 E / 3$ & 0 \\
$V_{4}$ & 0 & 1 & 1 & 0 & $2 E / 3$ & $2 E / 3$ \\
$V_{5}$ & 0 & 0 & 1 & 0 & 0 & $2 E / 3$ \\
$V_{6}$ & 1 & 0 & 1 & $2 E / 3$ & 0 & $2 E / 3$ \\
$V_{7}$ & 1 & 1 & 1 & $2 E / 3$ & $2 E / 3$ & $2 E / 3$ \\
\hline
\end{tabular}

\subsection{DFIM model}

Three-phase model. In order to represent the DFIM independently of the number of pole pairs, $N_{p}$ [5], we introduce $\theta$ as the electrical angle. We formulate the general equations describing the DFIM electrical behaviour as:

The first matrix equation (3) links the stator and rotor flux, $\Phi_{S_{a b c}}, \Phi_{R_{a b c}}$, with the 3-phase currents thanks to the inductance matrix:

$$
\left[\begin{array}{l}
{\left[\Phi_{S_{a b c}}\right]} \\
{\left[\Phi_{R_{a b c}}\right]}
\end{array}\right]=\left[\begin{array}{cc}
{\left[L_{s}\right]} & {\left[M_{r s}\right]} \\
{\left[M_{r s}\right]} & {\left[L_{r}\right]}
\end{array}\right]\left[\begin{array}{l}
{\left[I_{S_{a b c}}\right]} \\
{\left[I_{R_{a b c}}\right]}
\end{array}\right] .
$$

The second one links the stator and rotor voltages $V_{S_{a b c}}, V_{R_{a b c}}$ with the 3-phase flux and currents:

$$
\left[\begin{array}{l}
{\left[V_{S_{a b c}}\right]} \\
{\left[V_{R_{a b c}}\right]}
\end{array}\right]=\left[\begin{array}{l}
{\left[R_{s}\right]} \\
{\left[R_{r}\right]}
\end{array}\right]\left[\begin{array}{l}
{\left[I_{S_{a b c}}\right]} \\
{\left[I_{R_{a b c}}\right]}
\end{array}\right]+\frac{d}{d t}\left[\begin{array}{l}
{\left[\Phi_{S_{a b c}}\right]} \\
{\left[\Phi_{R_{a b c}}\right]}
\end{array}\right] .
$$




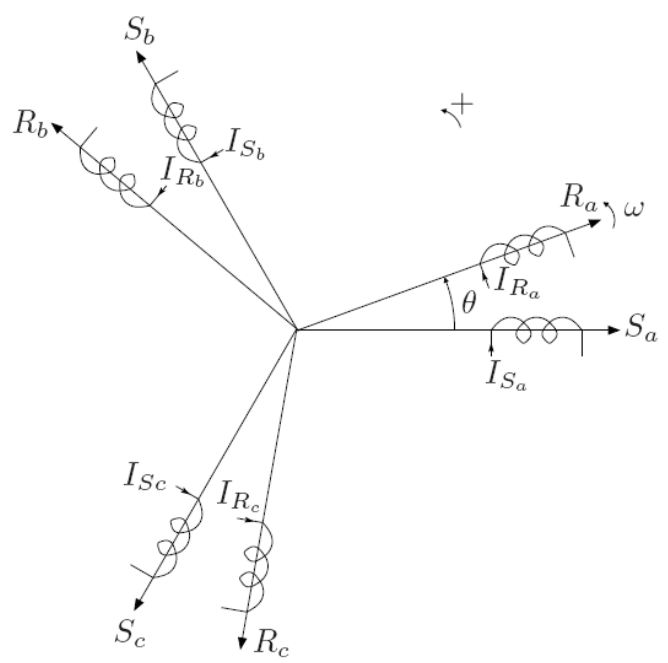

Fig. 5. 3-phase reference frame

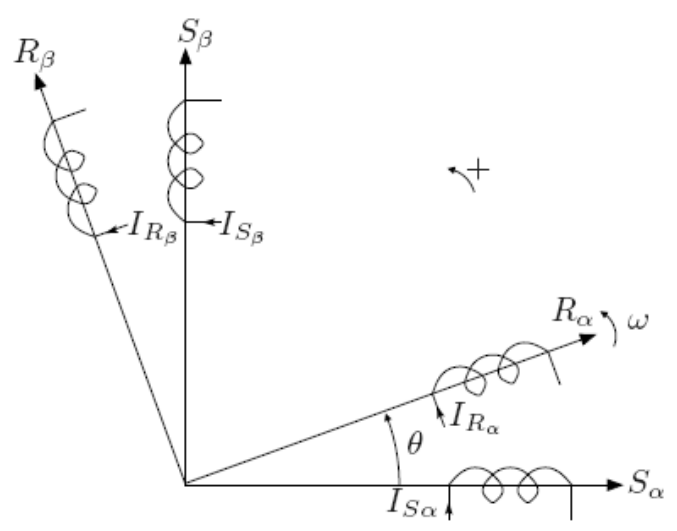

Fig. 6. Two-phase reference frame

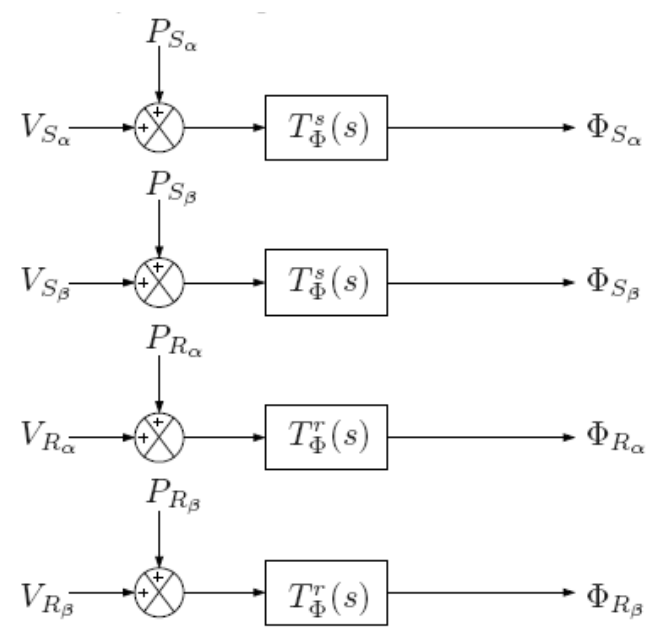

Fig. 7. DFIM flux blok diagram

Then, the stator and rotor resistor matrix, $\left[R_{s}\right],\left[R_{r}\right]$ are expressed.

The model expressed in a space diagram is given in Fig. 5. Where $I_{S a}, I_{S b}, I_{S c}$ are the 3-phase stator currents of the stator windings noted $S_{a}, S_{b}, S_{c} . I_{R a}, I_{R b}, I_{R c}$ are the 3-phase rotor currents associated to the rotor windings $R_{a}, R_{b}, R_{c} . \omega$ is the electrical speed of the rotor defined in the fixed stator reference frame.

We saw in Section 2 that our aim is to obtain a flux model. In order to define a simple model which links the flux to the stator and rotor voltages, we apply the Concordia three-phase two- phase transformation. Moreover, we define the stator and rotor fluxes as the new state variables.

Two-phase model. The three-phase/two-phase usual transformation is made with the power invariance hypothesis. During this study, we suppose that the homopolar component is null. We also suppose that the stator and rotor winding neutral points are not connected. Thus, we obtain DFIM representation as follows:

- the stator windings are placed in the stator stationary reference frame $\left(S_{\alpha}, S_{\beta}\right)$

- the rotor windings are placed in the rotor stationary reference frame $\left(R_{\alpha}, R_{\beta}\right)$. This reference frame is linked to the stator frame by its angular velocity $\omega_{s}$.

Figure 6 shows this reference frame where $I_{S \alpha}, I_{S \beta}$ are the stator currents, and $I_{R \alpha}, I_{R \beta}$ the rotor currents. We can express the two-phase equations describing the electrical behaviour as below:

$$
\begin{gathered}
{\left[\begin{array}{l}
{\left[\phi_{S_{\alpha \beta}}\right]} \\
{\left[\phi_{R_{\alpha \beta}}\right]}
\end{array}\right]=\left[\begin{array}{cc}
{\left[L_{s}\right]} & {[M(\theta)]} \\
{[M(\theta) \top]} & {\left[L_{r}\right]}
\end{array}\right]\left[\begin{array}{l}
{\left[I_{S_{\alpha \beta}}\right]} \\
{\left[I_{R_{\alpha \beta}}\right]}
\end{array}\right] .} \\
{\left[\begin{array}{l}
{\left[V_{S_{\alpha \beta}}\right]} \\
{\left[V_{R_{\alpha \beta}}\right]}
\end{array}\right]=\left[\begin{array}{l}
{\left[R_{s}\right]} \\
{\left[R_{r}\right]}
\end{array}\right]\left[\begin{array}{l}
{\left[I_{S_{\alpha \beta}}\right]} \\
{\left[I_{R_{\alpha \beta}}\right]}
\end{array}\right]+\frac{d}{d t}\left[\begin{array}{l}
{\left[\Phi_{S_{\alpha \beta}}\right]} \\
{\left[\Phi_{R_{\alpha \beta}}\right]}
\end{array}\right] .}
\end{gathered}
$$

In Eqs. 5 and 6, we defined some inductance matrix not detailed in this paper (but detailed in [6]). Thanks to this model, we can easily solve this equation system and express the voltages $\left(V_{S \alpha \beta}, V_{R \alpha \beta}\right)$ according to the two-phase flux $\left(\Phi_{S \alpha \beta}, \Phi_{R \alpha \beta}\right)$. The solving of this system (unexplained in this paper) gives some expressions which can be shown by the block diagram in Fig. 7. This figure presents the general block diagram of the DFIM two-phase model. We express the Laplace operator as s and obtain some disturbance terms noted $P_{S \alpha}, P_{S \beta}, P_{R \alpha}, P_{R \beta}$, defined as follows:

$$
\begin{gathered}
\left\{\begin{array}{l}
P_{S \alpha}=-\frac{M}{\sigma T_{s} L_{r}}\left(\Phi_{R \beta} \sin \theta-\Phi_{R \alpha} \cos \theta\right) \\
P_{S \beta}=\frac{M}{\sigma T_{s} L_{r}}\left(\Phi_{R \alpha} \sin \theta+\Phi_{R \beta} \cos \theta\right) \\
P_{R \alpha}=\frac{M}{\sigma T_{r} L_{s}}\left(\Phi_{S \beta} \sin \theta+\Phi_{S \alpha} \cos \theta\right) \\
P_{R \beta}=-\frac{M}{\sigma T_{r} L_{s}}\left(\Phi_{S \alpha} \sin \theta-\Phi_{S \beta} \cos \theta\right)
\end{array}\right. \\
\text { where }\left\{\begin{array}{l}
T_{s}=\frac{L_{s}}{R_{s}}: \text { electric stator time constant } \\
T_{r}=\frac{L_{r}}{R_{r}}: \text { electric rotor time constant } \\
\theta \quad \text { : electric rotor position }
\end{array}\right.
\end{gathered}
$$

We can defined two transmittances terms, which are linked to the stator windings $S_{\alpha}, S_{\beta}$ and to the rotor windings $R_{\alpha}, R_{\beta}$ respectively:

$$
\left\{\begin{array}{l}
T_{\Phi}^{s}(s)=\frac{\sigma T_{s}}{1+\sigma T_{s} s} \\
T_{\Phi}^{r}(s)=\frac{\sigma T_{r}}{1+\sigma T_{r} s}
\end{array}\right.
$$


Reduced model. We adopt a "standard" assumption for the considered frequencies. It consists in neglecting the resistive effect in the windings compared with the inductive effect. We can observe that this assumption is especially valid for high power machines. Consequently, we can express:

$$
\begin{gathered}
\sigma T_{s} s \gg 1 \text { for } s \rightarrow \infty \\
\sigma T_{r} s \gg 1 \text { for } s \rightarrow \infty \\
\text { So: }\left\{\begin{array}{rl}
T_{\Phi}^{s}(s)=\frac{\sigma T_{s}}{1+\sigma T_{s} s} \simeq \frac{1}{s} \text { when } \quad s \rightarrow \infty \\
T_{\Phi}^{r}(s)=\frac{\sigma T_{r}}{1+\sigma T_{r} s} \simeq \frac{1}{s} \text { when } \quad s \rightarrow \infty
\end{array} .\right.
\end{gathered}
$$

A second assumption is used. It consists in neglecting the coupling terms $P_{S \alpha}, P_{S \beta}, P_{R \alpha}, P_{R \beta}$. This can be done because the coupling terms are a low value in relation to the nominal values of the voltages level $V_{S \alpha}, V_{S \beta}, V_{R \alpha}, V_{R \beta}$. If we use the sign $\mathrm{n}$ for the nominal value of the considered term, this assumption can be expressed as below:

$$
\begin{aligned}
& P_{S_{\alpha}} \ll V_{S_{\alpha_{n}}} \\
& P_{S_{\beta}} \ll V_{S_{\beta_{n}}} \\
& P_{R_{\alpha}} \ll V_{R_{\alpha_{n}}} \\
& P_{R_{\beta}} \ll V_{R_{\beta_{n}}}
\end{aligned}
$$

Consequently, these two assumptions allow expressing the flux as the voltage integrals. In fact, the inverter switching time $\left(T_{e}\right)$ is significantly lower compared with the stator and rotor time constants $T_{s}$ and $T_{r}$.

Global model. Thanks to the VSI and DFIM models, we formulate the global scheme shown in Fig. 8. $H_{m}$ represents the mechanical transfer function. $H_{\text {load }}$ represents the load behaviour. $T_{m}$ is the load torque and $\Omega$ is the mechanical speed.

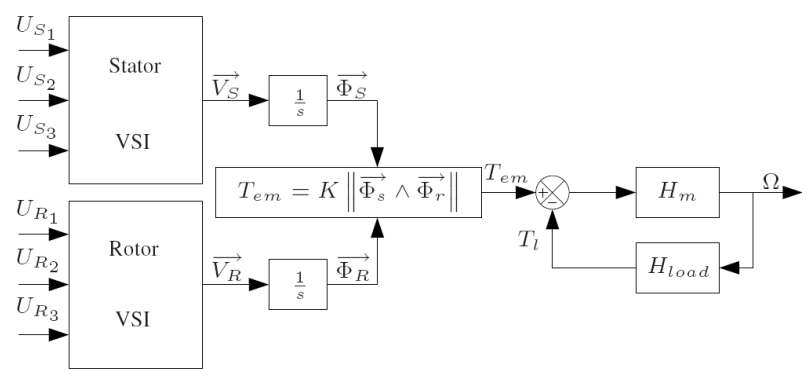

Fig. 8. Overall scheme of VSI and DFIM

\section{Direct torque control}

The switching sequences delivered to the IGBT drivers are selected in switching tables. These orders are calculated from the required DFIM electromagnetic states.

4.1. Principle of direct torque control. As shown by Fig. 8, the stator and rotor flux vectors can be directly linked to the stator and rotor voltage vectors.

$$
\left\{\begin{array}{l}
\frac{d}{d t} \vec{\Phi}_{s}=\vec{V}_{s} \\
\frac{d}{d t} \vec{\Phi}_{r}=\vec{V}_{r}
\end{array}\right.
$$

As previously expressed in [7], we integrate Eq. 13 during a sampling period $T_{e}$. Thus, Eq. 14 is obtained.

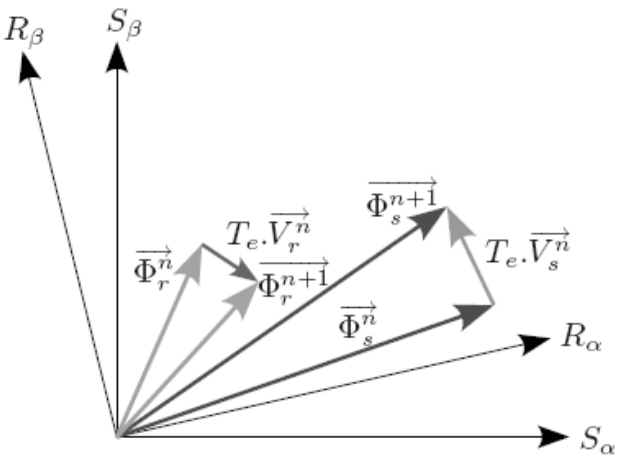

Fig. 9. Flux movement under voltage vectors

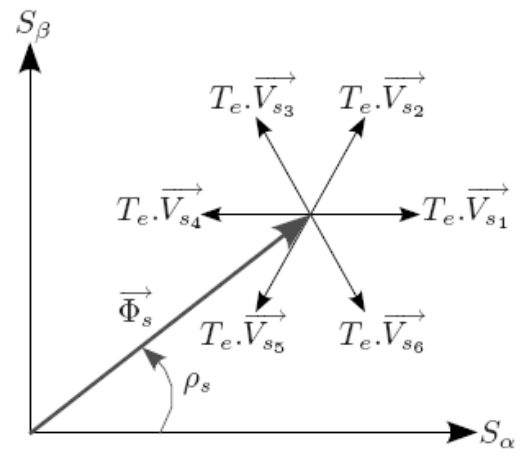

Fig. 10. Applicable voltage vectors for stator flux vector control

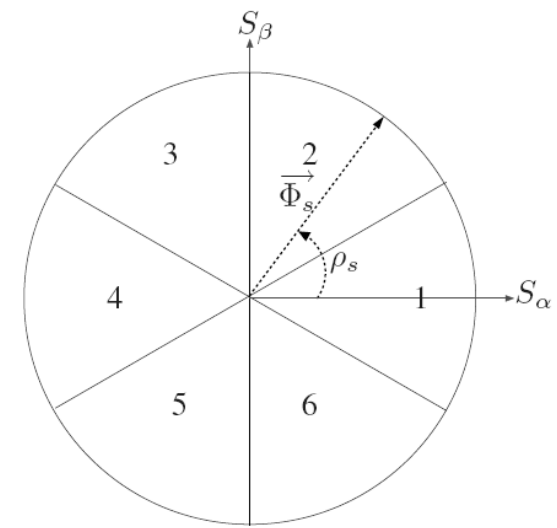

Fig. 11. The six sectors definition in the $(\alpha, \beta)$ reference frame

$$
\left\{\begin{array}{l}
\overrightarrow{\Phi_{s}\left(t_{n+1}\right)}=\overrightarrow{\Phi_{s}\left(t_{n}\right)}+T_{e} \cdot \overrightarrow{V_{s}\left(t_{n}\right)} \\
\overrightarrow{\Phi_{r}\left(t_{n+1}\right)}=\overrightarrow{\Phi_{r}\left(t_{n}\right)}+T_{e} \cdot \overrightarrow{V_{r}\left(t_{n}\right)}
\end{array} .\right.
$$

The voltage vector application time is $T_{e}$ (equal to the sampling time). Consequently $V_{s}$ and $V_{r}$ remain constant during the time interval $\left[t_{n} ; t_{n+1}\right]$ where $t_{n+1}=t_{n}+T_{e}$. Eq. 14 can be rewritten as follows:

$$
\begin{aligned}
& \overrightarrow{\Phi_{s}^{n+1}}=\overrightarrow{\Phi_{s}^{n}}+T_{e} \cdot \overrightarrow{V_{s}^{n}} \\
& \overrightarrow{\Phi_{r}^{n+1}}=\overrightarrow{\Phi_{r}^{n}}+T_{e} \cdot \overrightarrow{V_{r}^{n}}
\end{aligned}
$$




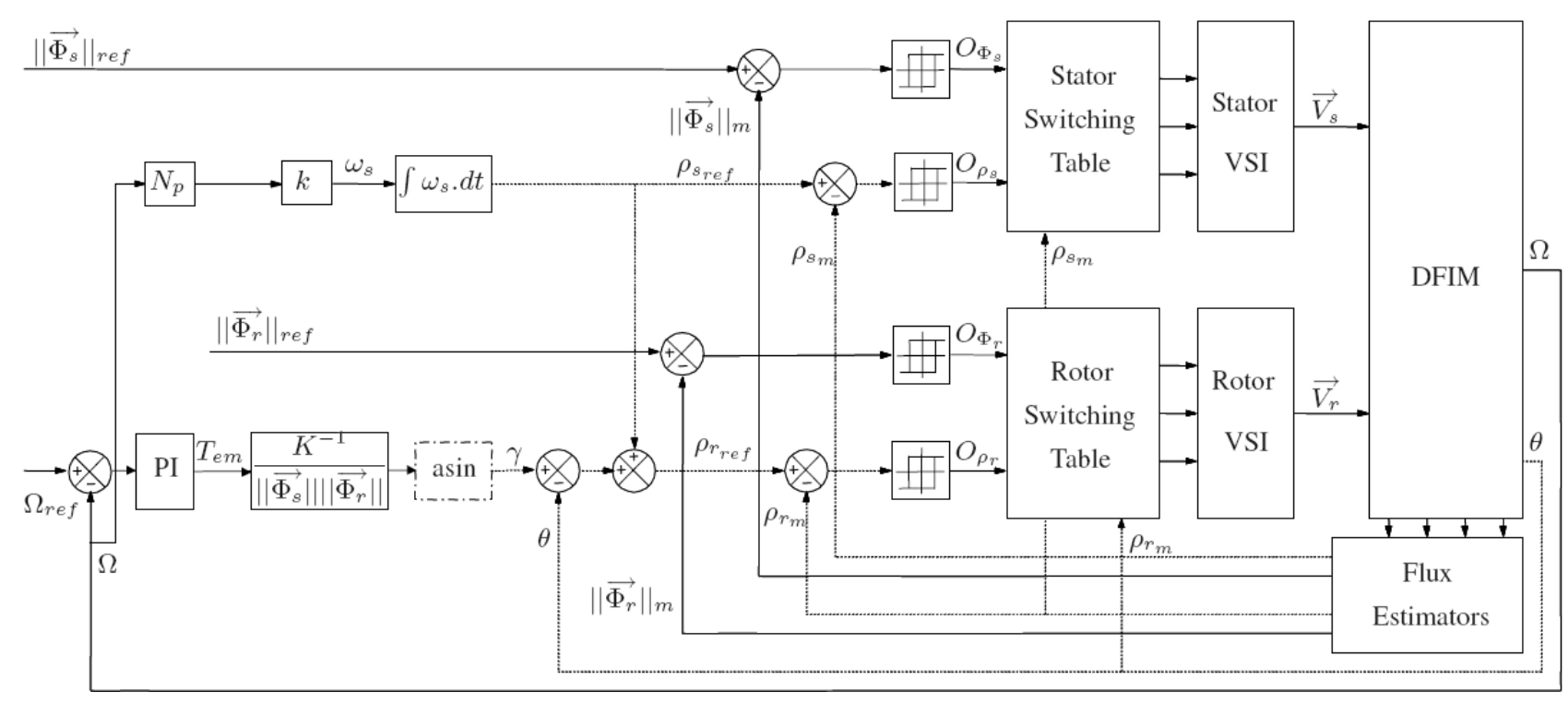

Fig. 12. General control strategy diagram

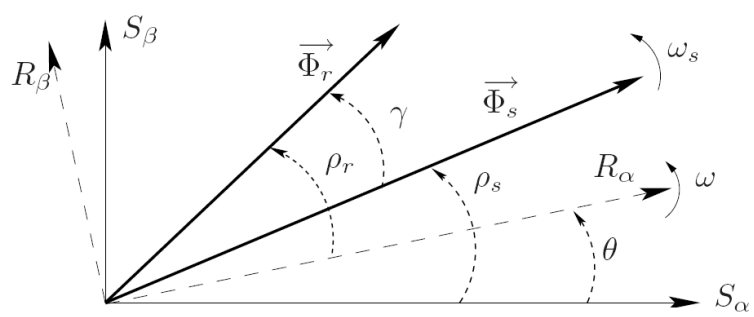

Fig. 13. Stator and rotor flux loci

Figure 9 illustrates Eq. 15. The flux vector end points move along a collinear straight line of the VSI voltage vectors. The new magnitude and phase of the required flux vector at time $t_{n+1}$ depends on:

- flux at time $t_{n}$

- supplied voltage vectors applied at time $t_{n}$.

The control strategy defines a required flux reference for each sampling time. The appropriate voltage vector on VSI outputs can be deduced from two estimated and two required values of stator and rotor flux. In Fig. 10, all applicable voltage vectors are shown. In this figure, only the stator flux example is given.

In this example, if $\overrightarrow{V_{S 1}}$ is applied, the magnitude of $\overrightarrow{\Phi_{s}}$ increase. Whereas the angular position $\left(\rho_{s}\right)$ of $\overrightarrow{\Phi_{s}}$ decrease. When a specific voltage vector is applied, the evolution of $\rho_{s}$ and the magnitude of $\overrightarrow{\Phi_{s}}$ can differ according to the $\rho_{s}$ initial value. Therefore, we define six sectors in the stationary $(\alpha, \beta)$ reference frame given in Fig. 11. Consequently, if $\overrightarrow{\Phi_{s}}$ is in the same sector, use of identical voltage vector leads to a similar phase and magnitude evolution of the flux vector. We manage the rotor flux vector in the same way.

Thus, the voltage vector to apply depends on:

- the sector number (according to $\rho_{s}$ and $\rho_{r}$ ),

- the required flux angular position,

- the required flux magnitude evolution.

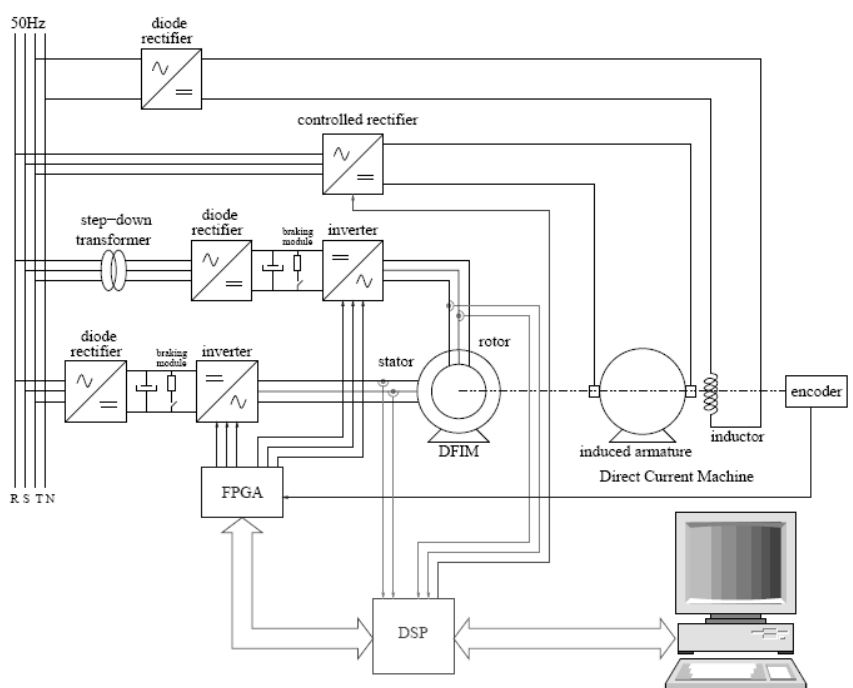

Fig. 14. Experimental system

Table 2

Switching table

\begin{tabular}{cccccccc}
\hline \hline & \multicolumn{7}{c}{ Sector number } \\
\hline$\vec{\Phi}$ evolution & 1 & 2 & 3 & 4 & 5 & 6 \\
\hline$\|\vec{\Phi}\|$ & $\rho$ & \multicolumn{7}{c}{ Voltage vector } \\
\hline$\nearrow$ & $\nearrow$ & $V_{2}$ & $V_{3}$ & $V_{4}$ & $V_{5}$ & $V_{6}$ & $V_{1}$ \\
$\nearrow$ & $\searrow$ & $V_{6}$ & $V_{1}$ & $V_{2}$ & $V_{3}$ & $V_{4}$ & $V_{5}$ \\
$\searrow$ & $\nearrow$ & $V_{3}$ & $V_{4}$ & $V_{5}$ & $V_{6}$ & $V_{1}$ & $V_{2}$ \\
$\searrow$ & $\searrow$ & $V_{5}$ & $V_{6}$ & $V_{1}$ & $V_{2}$ & $V_{3}$ & $V_{4}$ \\
\hline
\end{tabular}

This is illustrated by the switching table shown in Tab. 2 . Two independent switching tables are implemented in the control system. They allow controlling rotor and stator flux. Now, the direct torque control strategy is defined. Our purpose is to separate the stator and rotor flux adjustment. In this way, we 


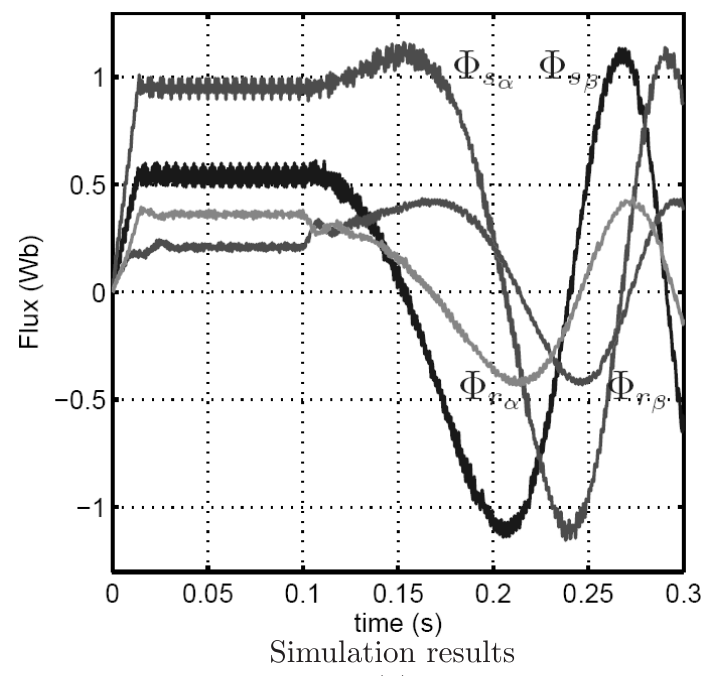

(a)

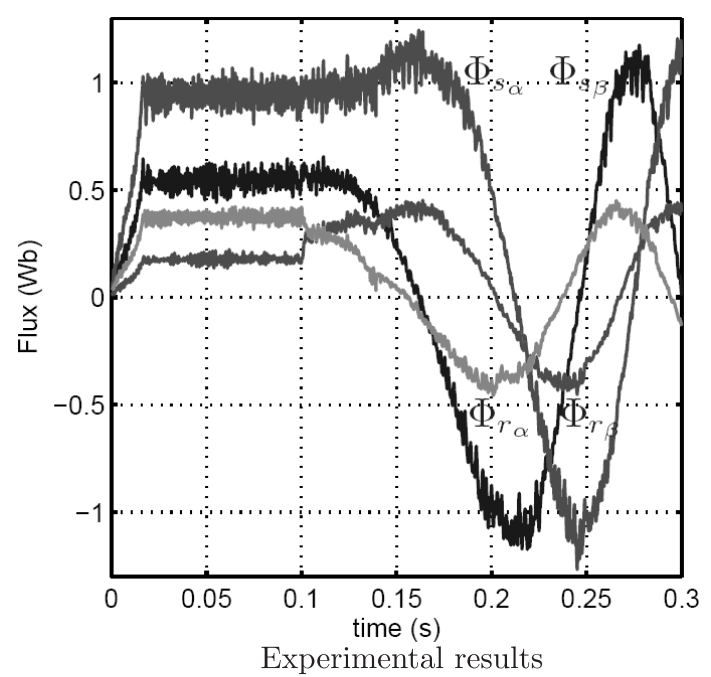

(b)

Fig. 15. Flux vector evolution during start-up

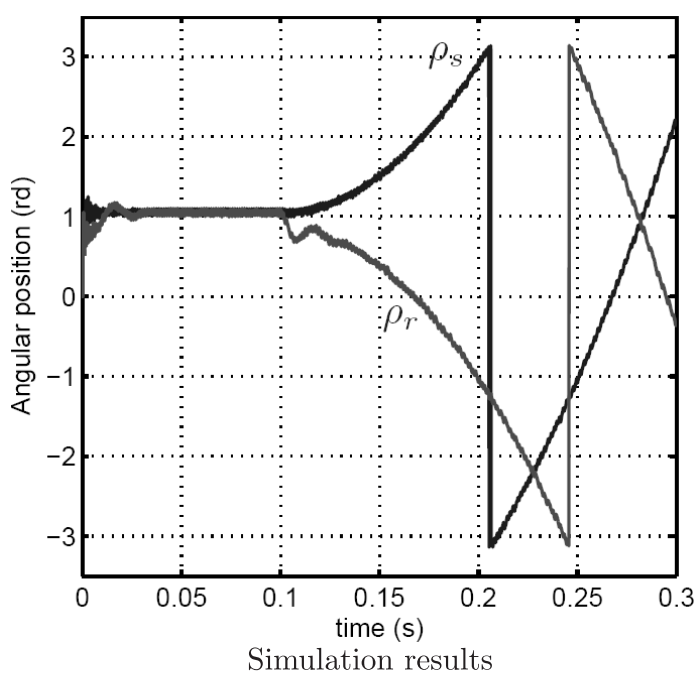

(a)

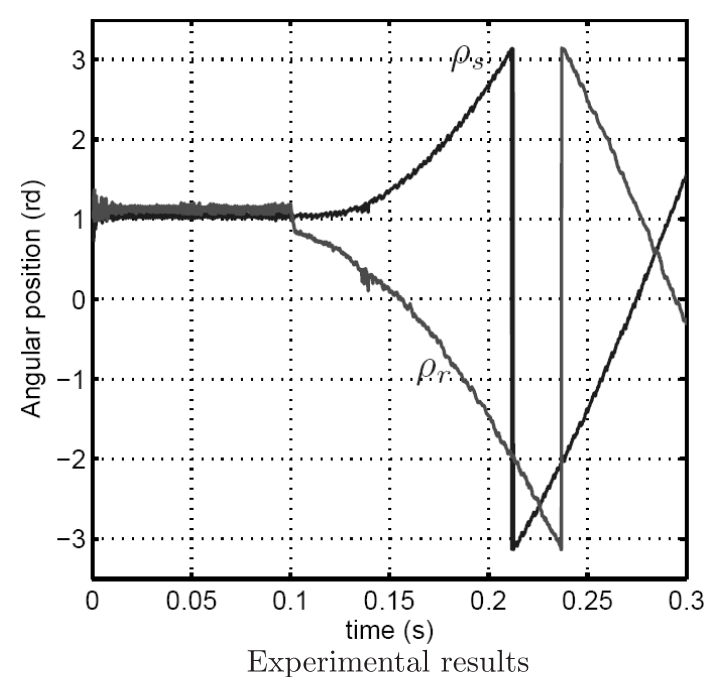

(b)

Fig. 16. Angular position control during start-up

control flux interaction, and consequently electromagnetic torque $T_{\text {em }}$ (Eq. (1)).

4.2. Direct torque control applied to the DFIM. We recall that the DFIM is constituted by sliding contacts between rotor winding connections and rotor windings. When the rotor is turning, we can only impose the rotor magnetic state in the rotor reference frame (not in the fixed stator reference frame). Figure 13 shows a new reference frame where $\omega_{s}$ is the stator flux angular speed. An angular relationship can be deduced as:

$$
\rho_{r}=\gamma-\theta+\rho_{s} .
$$

The control diagram set out in Fig. 12 shows the flux magnitude and phase control feedback. In this block diagram, $\Omega$ is the mechanical rotation speed.

First, we use two flux magnitude controllers. The flux mag- nitude reference values are constant and equal to their nominal values. The estimated values of flux are obtained by currents measurement. Input of hysteresis controllers are the difference between reference values and estimated values of flux magnitudes. Output of these controllers $\left(O_{\Phi s}, O_{\Phi r}\right)$ are connected to appropriate switching table.

Next, we use two angular position flux controllers. For the stator flux reference $\rho_{s_{\text {ref }}}$, the flux position value only depends on measured mechanical speed. For the rotor flux reference $\rho_{r_{r e f}}$, the flux position value depends on torque angle $\gamma$, rotor position $\theta$ and stator flux position reference $\rho_{s_{r e f}}$ as shown in Eq. 16. After the hysteresis controllers, we define two flux position orders $\left(O_{\rho_{s}}, O_{\rho_{r}}\right)$.

The speed control is carried out by a PI controller. Moreover, there is torque saturation. Consequently, we use an antiwindup block in order to minimize the speed response time. 

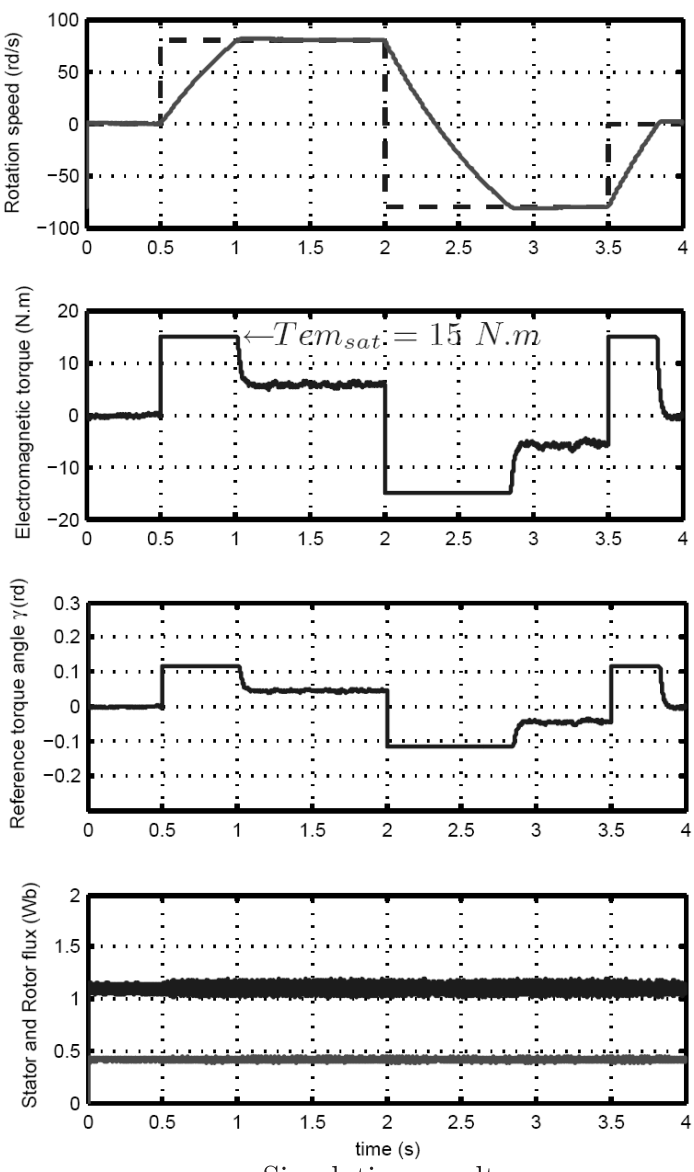

Simulation results

(a)
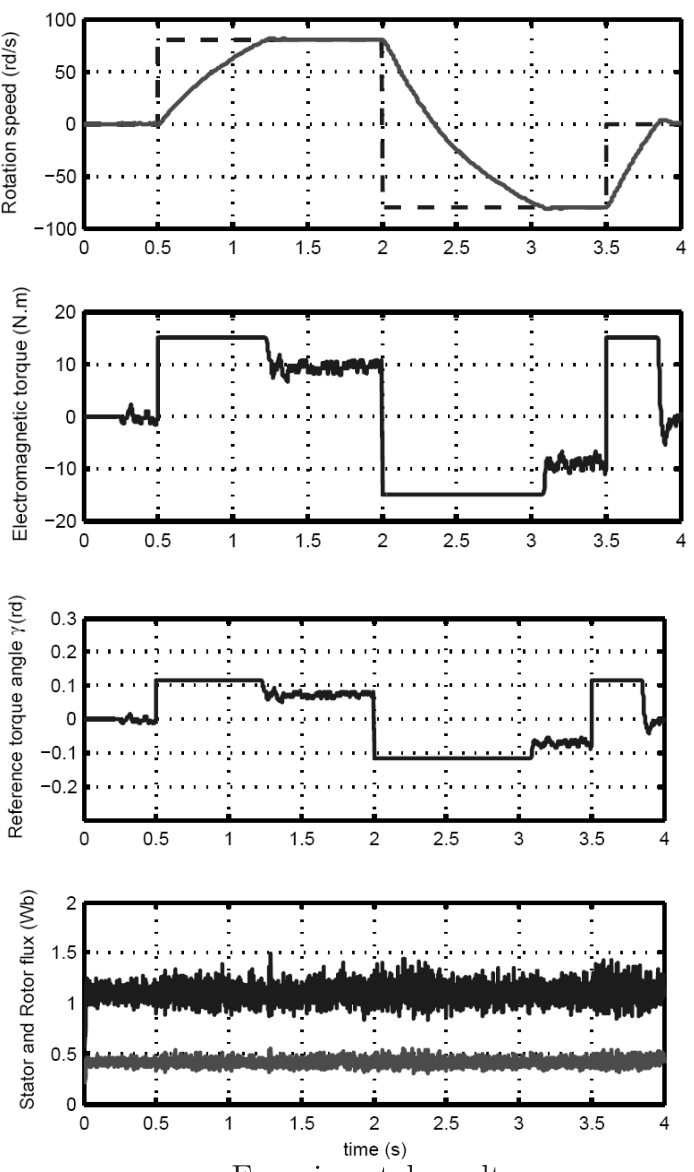

Experimental results

(b)

Fig. 17. Speed tracking performance

In Fig. 12, these blocks are not shown in order to simplify the block diagram. According to [8], a ratio k allows fixing the angular velocity degree of freedom $\omega$ in Fig. 12.

\section{Experimental results}

5.1. Introduction. In this section, the experimental device and some results are shown. This device uses:

- Doubly Fed Induction Machine (4 kW, $25 \mathrm{Nm}$ )

- MITSUBISHI 1200V - 75A intelligent IGBT power module

- DSP TMS 320C (Texas Instruments)

- FGPA EP1K 100 an ACEX 1K family (ALTERA).

The configuration of the experimental set-up is built around the DFIM stator and rotor windings. As shown in Fig. 14, two VSI are supplied by two independent DC links with different voltage levels. Indeed, a step-down transformer is used. Its primary windings are connected to the grid and its secondary windings to the rotor rectifier. Furthermore, we use a DC machine with a controlled rectifier to apply a variable load torque. The IGBT module is composed of three legs and a supplementary IGBT is used for the braking stage. Simulation is designed to examine the system behaviour. The DFIM drive and its control are simulated in the SABER software environment. The model of the physical process, is coding in MAST language, which is the SABER internal language. Whereas, the control laws are sampled and established in C language, and linked with MAST templates. Simulation control laws are similar to experimental control laws coded in the DSP. Main parameters of the experimental set-up are given in Tab. 3 .

\subsection{Comparison between simulation and experimental flux control}

Evolution of the flux vector components. Figure 15 shows $\alpha$ and $\beta$ component of stator and rotor flux. At time $t=0.1 \mathrm{~s}$, the mechanical speed reference change (start-up), and we can also see an abrupt change of rotor flux components. In fact, in Fig. 12 there is a step change of speed reference $\Omega_{\text {ref }}$. So, the speed controller output $T_{e m}$ presents also a step change. Consequently, the reference torque angle $\gamma$ and reference of the rotor flux position $\rho_{r_{r e f}}$ evolves.

Experimental phase control of flux. Figure 16 shows the stator and rotor flux phases during start-up.

Similar to Fig. 15, we can see an abrupt change of angular position of rotor flux due to the start-up. To conclude, experimental results show that we are able to control the angular position and magnitude of stator and rotor flux vector.

Speed control performance. In order to show the variable 
speed drive behaviour, we use the speed reference cycle shown in Fig 17. The mechanical speed behaviour is satisfactory with regard to the imposed speed cycle. The speed reference presents some step changes. To eliminate over currents in the machine, we choose a torque saturation value to $15 \mathrm{Nm}$. This experiment shows the behaviour of the PI controller and its anti-windup, and also the direct torque control scheme developed in this study.

Table 3

System parameters

\begin{tabular}{llc}
\hline \hline DFIM nominal power & $P$ & $4 \mathrm{~kW}$ \\
DFIM nominal rotation speed & $N$ & $1500 \mathrm{rpm}$ \\
Stator self inductance & $L_{s}$ & $0.163 \mathrm{H}$ \\
Rotor self inductance & $L_{r}$ & $0.021 \mathrm{H}$ \\
Maximum of mutual inductance & $M_{s r}$ & $0.055 \mathrm{H}$ \\
Stator resistance & $R_{s}$ & $1.417 \Omega$ \\
Rotor resistance & $R_{r}$ & $0.163 \Omega$ \\
Total viscous frictions & $f_{t}$ & $0.0073 \mathrm{~N} . \mathrm{m} /(\mathrm{rad} / \mathrm{s})$ \\
Total inertia & $J_{t}$ & $0.066 \mathrm{Kg} \cdot \mathrm{m}^{2}$ \\
Stator nominal voltage & $V_{s n}$ & $230 \mathrm{~V}$ \\
Rotor nominal voltage & $V_{r n}$ & $130 \mathrm{~V}$ \\
Stator nominal current & $I_{s n}$ & $8.4 \mathrm{~A}$ \\
Rotor nominal current & $I_{r n}$ & $19 \mathrm{~A}$ \\
Nominal torque & $T_{n}$ & $25.5 \mathrm{~N} . \mathrm{m}$ \\
Sampling period & $T_{e}$ & $200 \mu \mathrm{s}$ \\
Reduced voltage level of stator DC bus & $E_{s}$ & $300 \mathrm{~V}$ \\
Reduced voltage level of rotor DC bus & $E_{r}$ & $100 \mathrm{~V}$ \\
\hline
\end{tabular}

\section{Conclusions}

This paper presents a novel strategy which uses two voltage source inverters and switching tables in order to control electromagnetic torque of DFIM via stator and rotor flux vector. Experimental and simulation results have shown correct flux vector control behaviour and speed tracking performances. The merits of this study can be summarized as follows:

- novel configuration with two VSI controlled by Dual-DTC with two switching tables strategy,

- development of flux based DFIM mathematical model,
- experimental results which validate proposed modelling and control strategy.

Further study and improvements will include:

- speed and position sensorless operation (to remove mechanical motion sensor),

- improvement of switching tables and controls laws,

- improvement of model (current model),

- reduction of Total Harmonic Distortion (THD) of stator and rotor currents.

Acknowledgments. Authors wish to express they gratitude to Marian P. Kazmierkowski from Warsaw University of Technology for his valuable discussions and comments during his stay as Visiting Professor in LEEI, Institut National Polytechnique, Toulouse, France.

\section{REFERENCES}

[1] W. Leonhard, Control of Electrical Drives, Berlin: SpringerVerlag, 1996.

[2] M.P. Kaźmierkowski and H. Tunia, Control of Converter-Fed Driver, Amsterdam: Elsevier-PWN, 1994.

[3] Y. Kawabata, E. Ejiogu, and T. Kawabata, "Vector controlled double inverter fed wound rotor induction motor suitable for high power drives", IEEE Trans. Industry Appl. 35 (5), 10581066 (1999).

[4] G.S. Buja and M.P. Kaźmierkowski, "Direct torque control of pwm inverter-fed ac motor - a survey," IEEE Trans. on Industrial Electronics 51 (4), (2004).

[5] J.P. Caron and J.P. Hautier, Modélisation et Commande de la Machine Asynchrone, Editions Technip, Paris 1995.

[6] F. Bonnet, P. Vidal, and M. Pietrzak-David, "Adaptive variable structure control of a doubly fed induction machine", Proc. of Int. Conf. Pelincec, Warsaw, on CD (2005).

[7] A.M. Arcker, "Contrôle direct du couple electromagnetique de machines asynchrones de grande puissance", Ph.D. Dissertation, Institut National Polytechnique de Toulouse, Enseeiht, Toulouse, 1999.

[8] P.E. Vidal and M. Pietrzak-David, "Stator flux oriented control of a doubly fed induction machine", Proc. EPE, Toulouse, on CD (2003). 